\title{
Honeybee products and edible insect powders improve locomotive and learning abilities of Ubiquilin-knockdown Drosophila
}

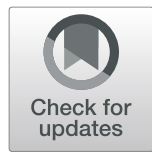

Patcharin Phokasem ${ }^{1,2}$, Salinee Jantrapirom ${ }^{3,4}$, Jirarat Karinchai ${ }^{5}$, Hideki Yoshida ${ }^{3,6}$, Masamitsu Yamaguchi $i^{3,6}$ and Panuwan Chantawannakul ${ }^{2,7^{*}}$

\begin{abstract}
Background: Mutations in the human Ubiquilin 2 gene are associated with neurodegenerative diseases such as amyotrophic lateral sclerosis (ALS) with or without frontotemporal dementia (FTD), the fatal neurodegenerative disease that progressively affected neuronal cells in both brain and spinal cord. There is currently no effective therapy for these diseases. Over the last decade, researchers have focused on the potential use of natural products especially in neurodegenerative studies. Insect products have been used as traditional medicines, however, scientific information is still lacking. Fruit fly is recently used as a model organism to investigate degenerative diseases related to the nervous system because it has a short life span and produces a large number of offspring.

Methods: The present study investigated the effects of honeybee products and edible insect powders on the locomotive and learning abilities, neuromuscular junctions (NMJs) structure, and reactive oxygen species (ROS) in larval brains of Ubiquilin- knockdown Drosophila.

Results: dUban knockdown flies showed defects in locomotive and learning abilities accompanied with structural defects in NMJs. The results obtained revealed that the recovery of locomotive defects was significantly greater in dUban knockdown flies fed with coffee honey from Apis cerana $(1 \% \mathrm{v} / \mathrm{v})$ or Apis dorsata melittin $(0.5 \mu \mathrm{g} / \mathrm{ml})$ or wasp powder $(2 \mathrm{mg} / \mathrm{ml})$ than that of in untreated dUban knockdown flies. Furthermore, dUban knockdown flies fed with coffee honey showed the partial rescue of structural defects in NMJs, improved learning ability, and reduced the accumulation of ROS caused by dUban depletion in the brain over the untreated group.
\end{abstract}

Conclusion: These results suggest that coffee honey from Apis cerana contains a neuroprotective agent that will contribute to the development of a novel treatment for ALS/FTD.

Keywords: Coffee honey, Edible insect, Honeybee product, Neuroprotective agent, Ubiquilin

\footnotetext{
* Correspondence: panuwan@gmail.com

${ }^{2}$ Bee Protection laboratory, Department of Biology, Faculty of Science, Chiang Mai University, A. Meung, Chiang Mai 50200, Thailand

${ }^{7}$ Environmental Science Research Center, Faculty of Science, Chiang Mai University, A. Meung, Chiang Mai 50200, Thailand

Full list of author information is available at the end of the article
}

C C The Author(s). 2020 Open Access This article is licensed under a Creative Commons Attribution 4.0 International License, which permits use, sharing, adaptation, distribution and reproduction in any medium or format, as long as you give appropriate credit to the original author(s) and the source, provide a link to the Creative Commons licence, and indicate if changes were made. The images or other third party material in this article are included in the article's Creative Commons. licence, unless indicated otherwise in a credit line to the material. If material is not included in the article's Creative Commons licence and your intended use is not permitted by statutory regulation or exceeds the permitted use, you will need to obtain permission directly from the copyright holder. To view a copy of this licence, visit http://creativecommons.org/licenses/by/4.0/ The Creative Commons Public Domain Dedication waiver (http://creativecommons.org/publicdomain/zero/1.0/) applies to the data made available in this article, unless otherwise stated in a credit line to the data. 


\section{Background}

Entomophagy or eating insects as food is well known in many cultures worldwide. Edible insects are a promising, healthy, and sustainable source of high quality proteins, good amino acids, and various fatty acids and contain high contents of a number of micronutrients, such as the minerals copper, iron, magnesium, manganese, phosphorous, selenium, and zinc as well as vitamins [1, 2]. Besides insects, insect-derived products, such as honeybee products, are well known and have been used since ancient times [3-5]. Honeybees produce honey, royal jelly, propolis, pollen, honeybee wax, and venom, which are potentially beneficial to humans due to their bioactive compounds [6-9]. Honeybee products are also regarded as a potential source of natural antioxidants [10]. The antioxidant activities of honeybee products are linked to their polyphenol compounds [9, 11, 12]. Phenolic and flavonoid compounds are the most important group of antioxidant substances present in honeybee products. The diversity of the phenolic content and antioxidant capacity depends on the processing, handling, types of plants, honeybees species, climatic conditions, geographical region and storage of honeybee products [13-16].

Insects and insect-derived products have been used in traditional medicine, a practice known as entomotherapy $[17,18]$. In Chinese traditional medicine, insects and their products such as silkworms (Bombyx mori L., 1758) have been applied for more than 3,000 years [19]. The larvae of certain flies have been recognized as an effective treatment for infected wound healing [20]. In addition, house crickets (Acheta domesticus L., 1758) have been used to cure scabies, asthma, eczema, earache, rheumatism, urine retention, urinary incontinence and ophthalmological problems in Latin American [21]. Honeybees and their products (e.g. honey, royal jelly, and venom) have been recorded in traditional medicine or a so-called "apitherapy" to treat/prevent various diseases [4]. As known, honey contains a number of phenols, the important honey phenols including flavonols (quercetin, kaempferol, galangin, fisetin, and myricetin), flavones (apigenin, acacetin, chrysin, luteolin, genkwanin, wogonin, and tricetin), phenolic acids (caffeic acids), and flavanones (hesperidin) [11, 12, 16]. Of these compounds, the flavonoid quercetin has been reported to enhance the apoptotic abilities of anti-CD95 and recombinant tumour necrosis factor-related apoptosisinducing ligand (rTRAIL) in the treatment of acute lymphocytic leukemia [22]. Honey is also used for the cure of many human diseases skin disorders, gastrointestinal disorders, neurological diseases, cardiovascular disorders, and diseases of the intestine [23-28]. Royal jelly, a larval food of honeybees, is also used to treat a wide variety of diseases, such as asthma, anorexia, gastrointestinal ulcers, arteriosclerosis, anemia, hypo- or hypertension, anti-cancer, wound healing, and neurasthenia or inhibit sexual libido [29-33]. Moreover, the venom of the honeybee has been employed to reduce the symptoms of and ameliorate inflammatory and autoimmune diseases, such as multiple sclerosis, arthritis, rheumatism, chronic pain, asthma, neurological diseases, and dermatological conditions [34-40]. The final apitherapy product, honeybee pollen, is considered a health food with a wide range of therapeutic properties such as antifungal, antimicrobial, antiviral, antiinflammatory, immunostimulating, and the burn wound healing [41-44]. However, little is known about the in vivo effects of insects and insect-derived products which have long been consumed in a daily life especially on neurodegenerative diseases.

Amyotrophic lateral sclerosis (ALS) with or without frontotemporal dementia (FTD) as one of neurodegenerative disease that affects the motor neurons connecting the brain and spinal cord, leading to eventual paralysis and death, and a mean survival of 2-5 years of life after diagnosis [45]. Mutations in the gene encoding ubiquitin chaperone Ubiquilin 2 (UBQLN2) have been associated with the early onset of neurodegenerative diseases, including ALS/FTD [46-48]. Mutations in UBQLN2 have also been identified as a cause of the X-linked forms of ALS/FTD [49]. Furthermore, mutations in UBQLN2 have recently been detected in familial cases of amyotrophic lateral sclerosis (FALS) and frontotemporal lobar dementia (FTLD) [50]. Recent studies demonstrated that some ALS-related UBQLN2 mutants exhibited defects in ubiquitin-binding abilities that resulted in a failure to deliver ubiquitinated substrates to proteasomes for degradation [46].

The fruit fly Drosophila melanogaster is the most commonly used experimental model organism. The advantage of using $D$. melanogaster is its genetic similarity to humans because approximately $75 \%$ of human diseaseassociated genes have related sequences in D. melanogaster [51, 52]. Furthermore, Drosophila is emerging as a useful model organism for advancing our understanding of the pathogenic mechanisms of $U B Q L N s$-associated neurological diseases because of its simplicity; it carries a single orthologue of human $U B Q L N s$, called Drosophila Ubiquilin (dUbqn), which shows high similarity to both human UBQLN1 (50\% identity) and UBQLN2 (48\% identity), respectively, and also carries conserved functional domains [53]. Therefore, Drosophila larvae have widely used as a model to study human neurodegenerative diseases including ALS/FLTD based on the following three criteria [54]. Firstly, locomotive ability can be quantitatively evaluated by the crawling assay in larvae. The progressive impairment in locomotive ability of the ALS/FLTD fly models has been characterized through 
crawling assay at larval stage [54]. Secondly, the Drosophila larval neuromuscular junctions (NMJs) allow easy and quantitative analyses of structural connections between the motor neuron and the muscle [55]. It is also reported that locomotive ability defects of larvae are frequently accompanied by synapse structural defects at NMJs [54]. Thirdly, learning ability can be readily examined at larval stage of $d U b q n$ knockdown flies, which exhibited locomotive dysfunctions and cognitive impairments in combination with severe structural defects in NMJs and mushroom bodies [54].

Currently, there are only two drugs (riluzole and edaravone) approved by U.S. food and drug administration (FDA) bringing a new hope for ALS patients. Unfortunately, the long-term effects and side effects of these drugs are still insufficiently investigated [56]. Moreover, an accessibility of new drugs is still being a great burden in some developing countries. Recently, the screening of natural products is gaining an attention, because the products can be generally used in daily life and are considered lack of toxicity. Especially in the field of neurodegeneration, many of herbs and insect products such as curcumin and melittin, have been found to be effective to delay or prevent the disease progression in cell and animal models $[57,58]$. It is therefore of our interest to investigate whether honeybee products and edible insect powders have potential to rescue the neurological defects caused by Ubiquilin depletion using Drosophila as a model organism.

\section{Methods}

\section{Honeybee products and edible insect powders} preparation

We used 15 samples of insects and insect-derived products in this present study. Edible insects and honeybee products that we used in this study were obtained from Northern Thailand. These edible insects and honeybee products exhibited high nutrition values and also pharmacological properties such as antioxidant, antimicrobial, and anti-inflammatory activities $[9,16,59]$.

i. Honeybee products. Honeybee product samples and their honeybee producers were Apis mellifera (longan honey, tea pollen, and fresh royal jelly) and Apis cerana (coffee honey). Longan honey, coffee honey, and tea pollen samples were purchased from local suppliers in Chiang Mai, Thailand, and kept in a lightproof container at $23-25^{\circ} \mathrm{C}$ until used. Fresh royal jelly samples were kept at $-20^{\circ} \mathrm{C}$ until used. Melittin peptides (purity > 95\%) from different species of Apis in Thailand (A. cerana, A. dorsata, and $A$. florea) were synthetized from Bio Basic Canada Inc. (Lot: 20180726, Markham, Ontario,
Canada). All samples were kept at $-20^{\circ} \mathrm{C}$ until used.

ii. Edible insects. Bombyx mori (silkworm (larvae)), Gryllus bimaculatus (crickets (adult)), Lethocerus indicus (giant water bug (adult)), A. mellifera (European honeybee queen (larvae)), Vespa affinis (wasp (pupae)), Pompania sp. (cicada (pupae)), Omphisa fuscidentalis (bamboo borer (larvae)), and Carebara castanea (subterranean ant (adult)) were purchased in March - April 2018 from a local supplier in the northern area of Thailand. All samples were certified and authorized for human consumption. Samples were kept at $-20^{\circ} \mathrm{C}$ until used for experiments.

iii. Edible insect powders and royal jelly powder preparation. Freeze-dried fresh royal jelly (FDRJ), samples were prepared from fresh royal jelly and stored at $-20^{\circ} \mathrm{C}$. Pooled frozen samples were thawed and filtered. After filtration, liquid royal jelly was converted into a powder using a vacuum dryer. Freeze-dried royal jelly powder (FDRJ) was obtained. In each species of edible insects, individuals were pooled and homogenized with a blender. The mixture was filtered with a 100-mesh filter, followed by Whatman No.1 filter paper. After filtration, samples were freeze-dried. Freeze-dried edible insects and FDRJ were packed in a lightproof container and stored at $4{ }^{\circ} \mathrm{C}$ until used in the present study.

\section{Fly stocks and maintenance}

All flies were cultured at $25^{\circ} \mathrm{C}$ with standard Drosophila food containing agar $(0.65 \% \mathrm{w} / \mathrm{v})$, glucose $(10 \% \mathrm{w} / \mathrm{v})$, dry yeast $(4 \% \mathrm{w} / \mathrm{v})$, corn flour $(5 \% \mathrm{w} / \mathrm{v})$, and rice powder $(3 \%$ $\mathrm{w} / \mathrm{v}$ ). Fly lines carrying $w ; U A S-d U b q n I R_{107-494 ;}+$ (ID 106050) were obtained from the Vienna Drosophila Resource Center (VDRC; Vienna, Austria). Fly lines carrying $w$; +; elav-GAL4 (RRID: BDSC_8760) and $w$; UAS-GFPIR;+ (RRID: BDSC_41550) were obtained from the Bloomington Drosophila Stock Center (BDSC; Bloomington, Indiana, USA).

\section{Drosophila culture and crosses}

The UAS/GAL4 system for gene silencing was used to knockdown $d U b q n$ in this study. Briefly, virgin females w;+; elav-GAL4 (RRID: BDSC_8760) which harbored the construct for pan-neuronal GAL4 expression, were crossed with $w / \mathrm{Y} ;$ UAS-dUbqnIR $107-494 ;+$ (ID 106050) males which carried the construct of transgenic expression of RNAi against $d U b q n$ at the region corresponding to the N-terminal dUbqn domain from aa position: aa 107 to aa 494 [54], inside the vials containing instant Drosophila medium blue (Carolina Biological Supply Company, Burlington, North Carolina, USA) with two concentrations of test samples mixed in (Supplementary 
Table S1 and S2) and maintained at $28^{\circ} \mathrm{C}$. The progenies (F1) which were knocked down of pan-neuronal dUbqn, were used to perform all experiments. The knockdown efficiency was confirmed by mRNA expression using quantitative RT-PCR. Forty of third instar larval whole brains were used for each genotype (control and dUbqn knockdown). Total RNA was extracted using the RNeasy Lipid Tissue Mini-Kit (Qiagen, Hilden, Germany) and following a DNase treatment (DNase I, Roche, Mannheim, Germany), 500 ng of total RNA was reversetranscribed to cDNA using the Primescript RT reagent kit (TaKaRa, Shiga, Japan) according to the manufacturer's instructions. Quantitative RT-PCR was performed in triplicate for each single extraction with the SYBR Green Master Mix: SYBR Premix Ex Taq II (Tli RNase H Plus, TaKaRa, Shiga, Japan) with the CFX96 Touch ${ }^{\text {Tx }}$ Real-Time PCR Detection System (Bio-Rad, USA) using the following specific primer pairs: dUbqn (F dUbqn 5'AACGCCCTTTGGCCTCAAT-3', R dubqn 5'-CAC CATCGGGTTGTCCATCA-3'); RpL32 (F RpL32 5'AGATCGTGAAGAAGCGCACC-3', R RpL32 5'-CGAT CCGTAACCGATGTTGG-3').

Samples were run in triplicate, and data were analyzed with a standard curve-based method calculated with CFX Manager ${ }^{\text {Tx }}$ software (Bio-Rad). The specificity of primers was tested with melt curves created by CFX Manager $^{\text {ma }}$ software. RpL32 was used as an internal control [54]. The dUbqn knockdown larvae without treatment were considered as untreated flies. All experiments, we used flies carrying $w$; UAS-GFPIR/+; elav-GAL4/+ as control flies. The uptake of food was confirmed by inspecting a blue color in the larval intestine. Third-instar larvae were selected by size and wandering behavior.

\section{Crawling assay}

A crawling assay was performed as described previously [60] with some modifications. Flies carrying $w$; UAS-

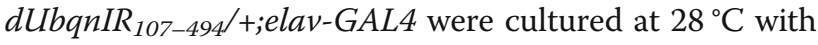
instant Drosophila medium containing two concentrations of insect and insect-derived product samples (Supplementary Table S1 and S2). Flies carrying $w$; UASGFPIR/+;elav-GAL4/+, (control flies) and w; UAS-dUbq-

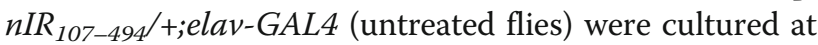
$28^{\circ} \mathrm{C}$ with instant Drosophila medium. Larvae at the third instar wandering stage were collected and washed with phosphate-buffered saline (PBS) to remove food traces. Larvae were then transferred into a $15-\mathrm{cm}$ Petri dish containing $2 \%(\mathrm{w} / \mathrm{v})$ agarose at a density of two larvae per plate. A 1-min video was acquired with a digital camera. Recorded videos were then converted to the AVI type using a MOV to AVI converter (Pazera Jacek, Poland) and analyzed by Image J software with the
wrMTrck plug-in to track larval movement and draw motion paths.

\section{Larval learning assay}

Third instar larvae earlier than the wandering stage were trained and tested for odor-taste learning performance according to previously described protocols [54], in which experiments were conducted on assay plates. Based on the results of locomotive abilities, we selected three treatments (coffee honey $(1 \% \mathrm{v} / \mathrm{v}), A$. dorsata melittin $(0.5 \mu \mathrm{g} / \mathrm{ml})$, and wasp powder $(2 \mathrm{mg} / \mathrm{ml}))$ for larval learning ability experiment. Flies carrying $w$; UAS-

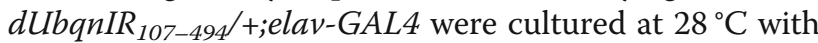
instant Drosophila media containing different tested samples (coffee honey $(1 \% \mathrm{v} / \mathrm{v})$, A. dorsata melittin $(0.5 \mu \mathrm{g} / \mathrm{ml})$, wasp powder $(2 \mathrm{mg} / \mathrm{ml}))$. Flies carrying $w$; UAS-GFPIR/+;elav-GAL4/+, (control flies) and $w$; UASdUbqnIR ${ }_{107-494 /+; e l a v-G A L 4}$ (untreated flies) were cultured at $28{ }^{\circ} \mathrm{C}$ with instant Drosophila medium. The learning assay is based on two phases. A group of larvae was firstly exposed to n-amyl acetate (AM; Merck, Darmstadt, Germany) in the presence of a reward (2 M sucrose, SUC) and then 1-octanol (OCT; Sigma, Steinheim, Germany) in the absence of SUC. This training was defined as $\mathrm{AM}+\mathrm{OCCT}$, with "+" indicating the reward. Reciprocal training was then carried out. The group of larvae was sequentially exposed to OCT in the presence of SUC and then AM in the absence of SUC. This training is defined as OCT+/AM. To allow flies to make an association between AM or OCT and the reward (SUC), five minutes of each training were performed and repeated three times. Each odorant used in the experiments (OCT and AM) were prepared by loading ten $\mu \mathrm{l}$ onto a $200 \mu \mathrm{l}-\mathrm{PCR}$ tube (perforated lid) with 7 holes and placed on the opposite site inside the Petri dish. Undiluted OCT was used, while AM was applied at a 1:50 dilution with liquid paraffin. Eighteen larvae for each corresponding training $(\mathrm{AM}+/ \mathrm{OCT}$ and $\mathrm{OCT}+/$ $\mathrm{AM}$, respectively) were then divided into three groups. Each group of larvae $(n=6)$ was tested by exposure to AM and OCT, which were deposited on the opposite ends of each test plate in the absence of SUC, for four minutes. Memory ability was evaluated by comparing the preference for the reward odorant against that for the no reward one. The preference indexes were used to calculate a learning index (LI).

\section{Visualization of NMJs}

Flies carrying $w$; UAS-dUbqnIR $107-494 /+$;elav-GAL4 were cultured at $28^{\circ} \mathrm{C}$ with instant Drosophila media containing different tested samples (coffee honey ( $1 \% \mathrm{v} / \mathrm{v}), A$. dorsata melittin $(0.5 \mu \mathrm{g} / \mathrm{ml})$, wasp powder $(2 \mathrm{mg} / \mathrm{ml}))$. We selected three treatments according to the locomotive abilities results. Flies carrying $w$; UAS-GFPIR/+;elav- 
GAL4/+, (control flies) and w; UAS-dUbqnIR $107-494 /+$; elav-GAL4 (untreated flies) were cultured at $28^{\circ} \mathrm{C}$ with instant Drosophila medium. Third instar larvae (10 larvae/group) were dissected in HL3 saline and fixed in 4\% paraformaldehyde in PBS at $25^{\circ} \mathrm{C}$ for 30 min [61] NMJs were stained as previously describe [62]. The blocking buffer contained $2 \%$ bovine serum albumin and $0.1 \%$ Triton X-100 in PBS buffer was used at $25^{\circ} \mathrm{C}$ for $30 \mathrm{~min}$. Fluorescein isothiocyanate (FITC)-conjugated goat antihorseradish peroxidase (HRP) IgG (1:1000 dilution, MP Biochemicals) was applied as the detection antibody and then probed with mouse monoclonal anti-Disc large (Dlg) (1:300 dilution, DSHB). After being washed with PBS buffer containing 0.3\% Triton X-100, samples were incubated with secondary antibodies labeled with Alexa 594 (1:400 dilution) at $25^{\circ} \mathrm{C}$ for $3 \mathrm{~h}$. After extensive washing with PBS containing $0.3 \%$ Triton X-100, stained samples were then mounted with ProLong Diamond (Invitrogen, USA) and MN 4 (Ib) on muscle number 4 belonging to abdominal segment 3 was observed and quantified under a confocal laser-scanning microscope (Fluoview FV10i, Olympus, Tokyo, Japan). Images were taken with a super resolution microscope (N-SIM, Nikon, Japan).

\section{Measurement of reactive oxygen species (ROS) levels}

Flies carrying $w$; UAS-dUbqnIR $107-494$-; elav-GAL4 were cultured at $28^{\circ} \mathrm{C}$ with instant Drosophila medium containing coffee honey $(1 \% \mathrm{v} / \mathrm{v})$. We selected the coffee honey $(1 \% \mathrm{v} / \mathrm{v})$ treatment base our study on learning abilities and NMJs structure. Flies carrying $w$; UAS-GFPI $R /+$;elav-GAL4/+, (control flies) and $w ; U A S-d U b q-$ $n I R_{107-494 /+; e l a v-G A L 4}$ (untreated flies) were cultured at $28{ }^{\circ} \mathrm{C}$ with instant Drosophila medium. The brains from third instar larvae of control, untreated, and coffee honey ( $1 \% \mathrm{v} / \mathrm{v})$-fed groups (20 larvae/group) were placed in $1 \times \mathrm{PBS}\left(17.5 \mathrm{mM} \mathrm{NaCl}, 8.41 \mathrm{mM} \mathrm{Na}_{2} \mathrm{HPO}_{4}\right.$, and 1.86 $\mathrm{mM} \mathrm{NaH} \mathrm{PO}_{4}, \mathrm{pH}$ 7.4). Larval brains from the control, untreated, and treated groups (20 larvae/group) were homogenized in cold $1 \times \mathrm{PBS}$ ( $\mathrm{pH}$ 7.4) followed by centrifugation at $12,000 \times g$ for $10 \mathrm{~min}$. Total ROS levels were measured in homogenates of the larval brains from control, untreated, and coffee honey ( $1 \% \mathrm{v} / \mathrm{v})$-fed groups using $2^{\prime}, 7^{\prime}$-dihydrofluorescein diacetate $\left(\mathrm{H}_{2}\right.$ DCFDA; Invitrogen) following the method reported previously [63] with minor modifications. Briefly, in brain homogenates, the dye was added at a final concentration of $10 \mu \mathrm{M}$ and incubated at $24 \pm 1^{\circ} \mathrm{C}$ for $1 \mathrm{~h}$ in the dark. The mixture was then placed on a microplate reader (Molecular Devices LLC, California, USA) for fluorescence quantification at an excitation/emission wavelength of $495 / 519 \mathrm{~nm}$. The mean fluorescence intensity was used to estimate ROS levels in each sample. Three samples from each group were analyzed in triplicate.

\section{Statistical analysis}

Statistical analyses were performed with GraphPad Prism version 6.02. The Mann-Whitney U test was used to test for significant differences between groups of independent data, while comparisons between groups were performed by the Kruskal-Wallis test or a two-way ANOVA followed by Dunnett's multiple comparison analysis. All data were shown as means \pm SEM. $P$ values of $<0.05$ were considered significant for all.

\section{Results \\ Honeybee products and edible insect powders feeding improved the locomotive activity of dUbqn knockdown larvae}

We examined the effects of insects and insect-derived products on the locomotive abilities of pan neuronspecific dUbqn knockdown larvae. To evaluate knockdown efficiency of dUbqn in the RNAi line, a transcriptional gene analysis was performed using RNA extracts from the third instar larval brains to measure the abundance of $d U b q n$ transcripts with respect to an internal control, $R p L 32$. The $d U b q n$ knockdown larvae showed 38\% reduction in dUbqn transcript levels from the control (Supplementary figure S1). The Drosophila strain using in the present study was previously confirmed for no off-target effects [54]. Using ImageJ, crawling parameters were quantified, including distance $(\mathrm{cm}$, distance from start to finish), speed $(\mathrm{cm} / \mathrm{min})$, and length ( $\mathrm{cm}$, total path length). We measured the distance covered in 1 minute by the treated larvae and compared it with those of untreated larvae (Fig. 1). The depiction of the larval path showed that untreated dUbqn knockdown larvae were confused and had a shorter crawling distance, whereas larvae treated with the samples described below moved linearly and covered a greater distance (Fig. 1a and b). The crawling distances of larvae treated with coffee honey $(1 \% \mathrm{v} / \mathrm{v})$, silkworm powder $(0.2 \mathrm{mg} / \mathrm{ml})$, giant water bug powder $(2 \mathrm{mg} / \mathrm{ml})$, cricket powder $(0.2 \mathrm{mg} / \mathrm{ml})$, wasp powder $(0.2,2 \mathrm{mg} / \mathrm{ml})$, and subterranean ant powder $(0.2 \mathrm{mg} / \mathrm{ml})$ were significantly longer than that of untreated larvae $(p=0.0151(n=20)$, $p=0.0119(n=20), p=0.0308 \quad(n=20), p=0.0281 \quad(n=$ $20), p=0.0025(n=20), p=0.0003(n=20)$, and $p=$ $0.0015(n=20)$, respectively) (Fig. 1a and b, $n=20)$. In contrast, the treatment of larvae with $A$. dorsata melittin $(0.5$ and $2 \mu \mathrm{g} / \mathrm{ml}), A$. cerana melittin $(0.5$ and $2 \mu \mathrm{g} / \mathrm{ml})$, A. florea melittin $(0.5$ and $2 \mu \mathrm{g} / \mathrm{ml})$, coffee honey $(0.1 \%$ $\mathrm{v} / \mathrm{v})$, longan honey $(0.1$ and $1 \% \mathrm{v} / \mathrm{v})$, tea pollen $(0.2$ and $2 \mathrm{mg} / \mathrm{ml}$ ), FDRJ $(0.2$ and $2 \mathrm{mg} / \mathrm{ml})$, cicada powder $(0.2$ and $2 \mathrm{mg} / \mathrm{ml})$, silkworm powder $(2 \mathrm{mg} / \mathrm{ml})$, bamboo borer powder $(0.2$ and $2 \mathrm{mg} / \mathrm{ml})$, honeybee larvae powder $(0.2$ and $2 \mathrm{mg} / \mathrm{ml})$, giant water bug powder $(0.2 \mathrm{mg} /$ $\mathrm{ml})$, cricket powder $(2 \mathrm{mg} / \mathrm{ml})$, and subterranean ant 


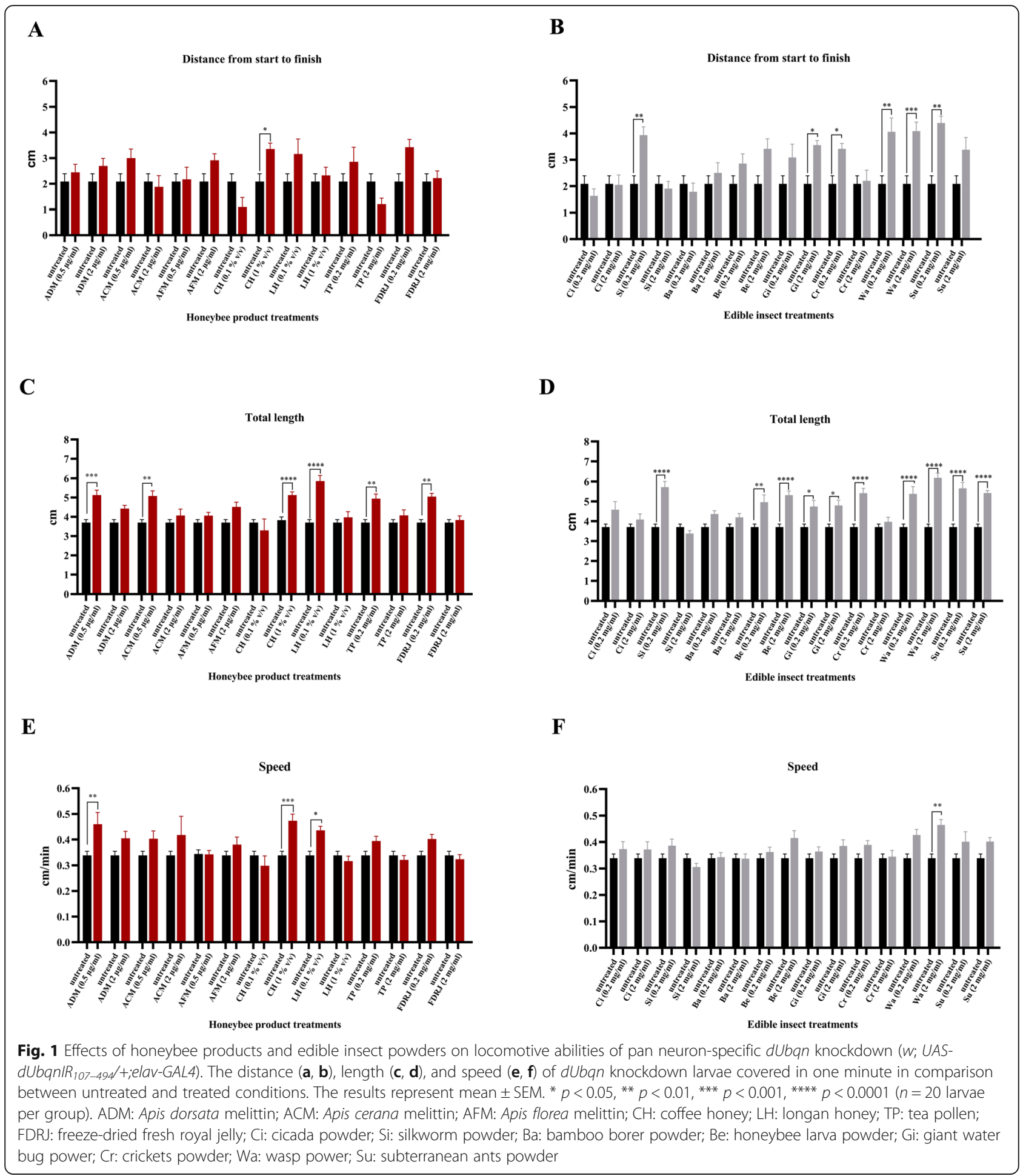

powder $(2 \mathrm{mg} / \mathrm{ml})$ did not significantly affect crawling distances.

The crawling speeds of pan neuron-specific $d U b q n$ knockdown larvae fed with coffee honey $(1 \% \mathrm{v} / \mathrm{v})$, longan honey $(0.1 \% \mathrm{v} / \mathrm{v}), A$. dorsata melittin $(0.5 \mu \mathrm{g} / \mathrm{ml})$, and wasp powder $(2 \mathrm{mg} / \mathrm{ml})$ were significantly faster than that of untreated larvae $(p=0.0002,(n=20), p=0.0236$ $(n=20), p=0.0096(n=20)$, and $p=0.046(n=20)$, respectively) (Fig. 1e and $\mathrm{f}, \mathrm{n}=20$ ). In contrast, the treatment of larvae with $A$. dorsata melittin $(2 \mu \mathrm{g} / \mathrm{ml}), A$. cerana melittin $(0.5$ and $2 \mu \mathrm{g} / \mathrm{ml})$, A. florea melittin $(0.5$ and $2 \mu \mathrm{g} / \mathrm{ml})$, coffee honey $(0.1 \% \mathrm{v} / \mathrm{v})$, longan honey ( $1 \%$ 
$\mathrm{v} / \mathrm{v})$, tea pollen $(0.2$ and $2 \mathrm{mg} / \mathrm{ml})$, FDRJ $(0.2$, and $2 \mathrm{mg} /$ $\mathrm{ml})$, cicada powder $(0.2$ and $2 \mathrm{mg} / \mathrm{ml})$, bamboo borer powder $(0.2$ and $2 \mathrm{mg} / \mathrm{ml})$, silkworm powder $(0.2$ and 2 $\mathrm{mg} / \mathrm{ml})$, giant water bug powder $(0.2$ and $2 \mathrm{mg} / \mathrm{ml})$, cricket powder $(0.2$ and $2 \mathrm{mg} / \mathrm{ml})$, wasp powder $(0.2 \mathrm{mg} /$ $\mathrm{ml})$, subterranean ant powder $(0.2$ and $2 \mathrm{mg} / \mathrm{ml})$, and honeybee larvae powder $(0.2$ and $2 \mathrm{mg} / \mathrm{ml})$ did not significantly increase crawling speeds. Collectively, these results indicate that three samples, coffee honey $(1 \% \mathrm{v} /$ $\mathrm{v})$, A. dorsata melittin $(0.5 \mu \mathrm{g} / \mathrm{ml})$, and wasp powder (2 $\mathrm{mg} / \mathrm{ml}$ ), are good candidates for improving the defects induced by the pan neuron-specific $d U b q n$ knockdown in D. melanogaster.

\section{Coffee honey feeding improved learning ability of $d U b q n$ knockdown larvae}

Based on their effects on locomotive ability, three treatments (coffee honey $(1 \% \mathrm{v} / \mathrm{v}), A$. dorsata melittin $(0.5 \mu \mathrm{g} / \mathrm{ml})$, and wasp powder $(2 \mathrm{mg} / \mathrm{ml}))$ were selected for further study on their effects on learning/memory abilities. We compared the learning ability of the treated groups with that of the untreated group. To investigate the effects of the three samples on the role of $d U b q n$ in complex neuronal functions, we performed a Drosophila larval odor-taste learning assay. Using this approach, we tested larvae carrying $w$; UAS-GFPIR/+;elav-GAL4/+ (control flies) and $w$; UAS-dUbqnIR $107-494 /+$;elavGAL4/+ (pan neuron-specific dUbqn knockdown flies) (Fig. 2). In the control larvae, the preference for the reward odorant was greater than that to the no reward odorant in accordance with training. The result displays their abilities to make the correct association between an odorant and reward (Fig. 2a). In dUbqn knockdown larvae (untreated flies), the AM preference index was not significantly higher in AM+/OCT than in $\mathrm{OCT}+1$ AM (Fig. 2b). These results indicate that dUbqn knockdown larvae did not make an association between the odorant and reward. Therefore, it clearly showed that the depletion of $d U b q n$ resulted in a reduction in learning abilities in $d U b q n$ knockdown larvae (Fig. 2f).

The dUbqn knockdown larvae treated with coffee honey $(1 \% \mathrm{v} / \mathrm{v})$ showed a greater preference to the reward odorant than to the no reward odorant in accordance with training (Fig. 2c). However, the treatment with A. dorsata melittin $(0.5 \mu \mathrm{g} / \mathrm{ml})$ and wasp powder $(2 \mathrm{mg} /$ $\mathrm{ml}$ ) did not improve the ability of dUbqn knockdown larvae to make an association between the odorant and reward (Fig. 2d and e). LI clearly showed that among these three treatments (coffee honey $(1 \% \mathrm{v} / \mathrm{v}), A$. dorsata melittin $(0.5 \mu \mathrm{g} / \mathrm{ml})$, and wasp powder $(2 \mathrm{mg} / \mathrm{ml}))$, only the coffee honey $(1 \% \mathrm{v} / \mathrm{v})$-treated group showed significantly better learning ability $(p<0.05)$ in learning performance (learning scores around 0.22) than the untreated group (Fig. 2f). These results indicate that coffee honey is solely effective for recovering the learning defects induced by the $d U b q n$ knockdown.

\section{Coffee honey feeding rescued the synapse structural defects at NMJs induced by the dUbqn knockdown}

We examined whether the three treatments (coffee honey $(1 \% \mathrm{v} / \mathrm{v}), A$. dorsata melittin $(0.5 \mu \mathrm{g} / \mathrm{ml})$, and wasp powder $(2 \mathrm{mg} / \mathrm{ml}))$ have abilities to rescue the synapse structural defects at NMJs. When we compared the structure of NMJs at larval segment A3 in muscle number 4 in third instar larvae with the pan neuronspecific knockdown of dUbqn ( $w$; UAS-dUbqnIR107$494 /+$;elav-GAL4/+) with a control flies ( $w$; UAS-GFPI $R /+$;elav-GAL4/+), the NMJ structure of dUbqn knockdown larvae (untreated flies) showed a significantly shortened main branch length $(90.3 \pm 3.8 \mu \mathrm{m}$, dUbqn knockdown larvae vs $106.6 \pm 5.6 \mu \mathrm{m}$, control larvae, $p<$ 0.05 , Fig. 3f) and a decrease in the number of boutons $(10.8 \pm 0.8$, dUbqn knockdown larvae vs $17.9 \pm 1.1$, control larvae, $p<0.05$, Fig. $3 g$ ). A significantly larger terminal bouton size was also observed in dUbqn knockdown larvae $\left(20.1 \pm 1.7 \mu \mathrm{m}^{2}\right.$, dUbqn knockdown larvae vs $12.3 \pm 1.2 \mu \mathrm{m}^{2}$, control larvae, $p<0.05$, Fig. 3i).

The reduced number of boutons in $d U b q n$ knockdown larvae was significantly rescued by the three treatments (Fig. 3g). Only coffee honey ( $1 \% \mathrm{v} / \mathrm{v})$ rescued the enlarged terminal bouton size induced by the $d U b q n$ knockdown (Fig. 3i). In contrast, the increase observed in NMJ arbor branch numbers in dUbqn knockdown flies was not significantly restored by these three treatments. Thus, coffee honey appeared to be the most effective at rescuing the synapse structural defects at NMJs induced by the $d U b q n$ knockdown.

\section{Coffee honey feeding reduced the accumulation of ROS in dUbqn knockdown flies}

Total ROS levels were measured in the homogenates of third instar larval brains. To elucidate the association between the knockdown of $d U b q n$ and oxidative stress, we measured ROS levels in the third instar larval brains of dUbqn knockdown flies. The results displayed that ROS levels in third instar larval brains were 1.7-fold higher in dUbqn knockdown larvae (untreated flies) than in control larvae (Fig. 4). These results suggest that the knockdown of dUbqn increased ROS levels in Drosophila larval brains. It is interesting to note that the ROS levels in third instar larval brains were 0.5-fold lower in $d U b q n$ knockdown larvae treated with coffee honey (1\% v/v) than in untreated dUbqn knockdown larvae (Fig. 4). These results clearly demonstrated that the knockdown of $d U b q n$ induced ROS levels, which may lead to oxidative stress, and coffee honey attenuated this oxidative stress. 
A

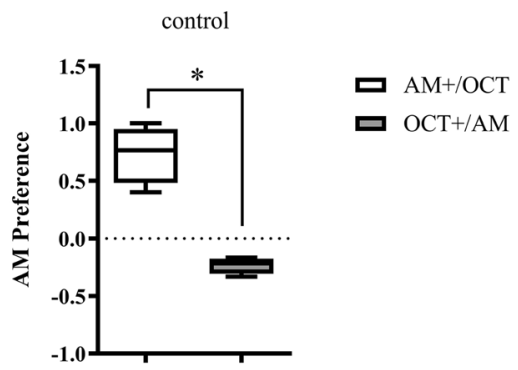

C coffee honey $(1 \% \mathrm{v} / \mathrm{v})$

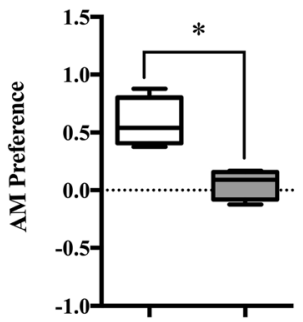

E wasp powder $(2 \mathrm{mg} / \mathrm{ml})$

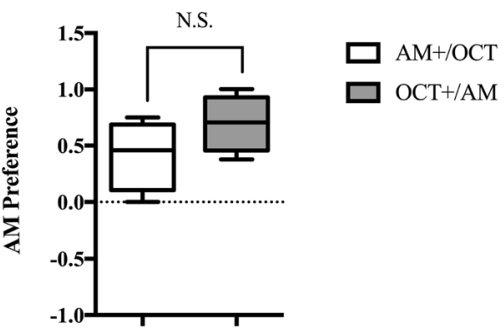
OCT $+/ \mathrm{AM}$
B

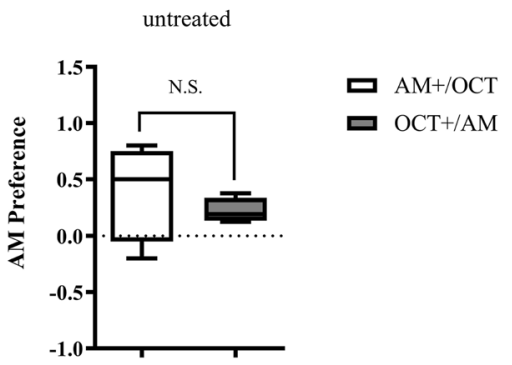

D

Apis dorsata melittin $(0.5 \mu \mathrm{g} / \mathrm{ml})$

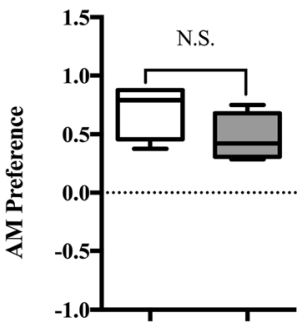

$\square \mathrm{AM}+/ \mathrm{OCT}$

$\square \mathrm{OCT}+\mathrm{AM}$

F

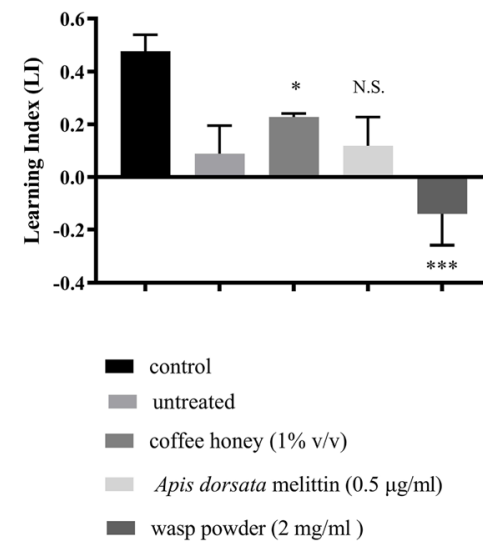

Fig. 2 Effects of honeybee products and edible insect powders on learning abilities of pan neuron-specific dUban knockdown larvae. The larvae were sequentially exposed to n-amyl acetate (AM) in the presence of reward and then 1-octanol (OCT) in the absence of reward (AM+/OCT). The reciprocal training the larvae was sequentially exposed to OCT in the presence of reward and AM in the absence of reward (OCT+/AM). After training, larvae were tested by exposure to AM and then OCT in the absence of reward to test their preference. Larval AM preference score was shown in (a-e) (score $=1$ means all preferred $A M$; score $=-1$ means all preferred OCT). The preference score of control larvae (W; UAS-GFPIR/ +;elav-GAL4/+) and dUban knockdown larvae ( ; $_{\text {; UAS-dUbanIR }}$ 107-494/+;elav-GAL4) without treatment was shown in (a, b) whereas the preference score of dUban knockdown larvae treated with coffee honey $(1 \% \mathrm{v} / \mathrm{v})$, A. dorsata melittin $(0.5 \mu \mathrm{g} / \mathrm{ml})$, and wasp powder $(2 \mathrm{mg} / \mathrm{ml})$ was shown in $(\mathbf{c}, \mathbf{d}, \mathbf{e})$. Box-and-whisker plots represent the minimum, first quartile, median, third quartile, and maximum. Normalized learning index of all groups was shown in (f). The higher $\mathrm{LI}$ means the higher ability of larvae to learn and perform the conditional tasks. The results represent mean \pm SEM. ${ }^{*} p<0.05$, N.S. not significant. ( $n=3$ of 6 larvae per group)

\section{Discussion}

ALS is a fatal neurodegenerative disease. Due to progressive neurodegeneration, ALS leads to paralysis and death by respiratory failure 2-5 years after the onset of symptoms and there is currently no effective therapy.
Mutations in the human $U B Q L N 2$ gene are associated with ALS/FTD. Insects and insect-derived products have been used in traditional medicine for various diseases. In the present study, we utilized the ALS/FTD model fly targeting the dUbqn gene. In addition, since Drosophila 

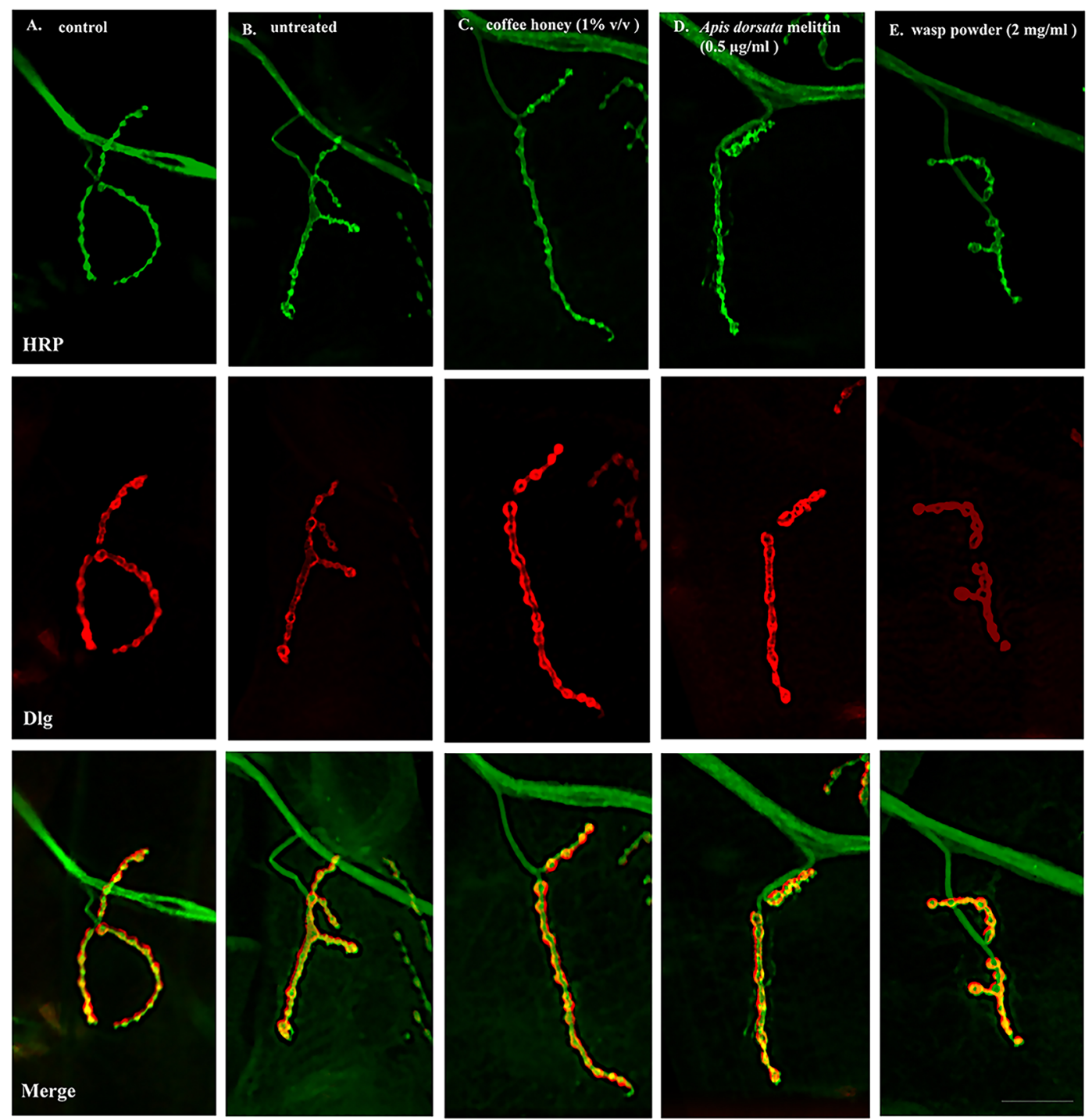

F.

G.
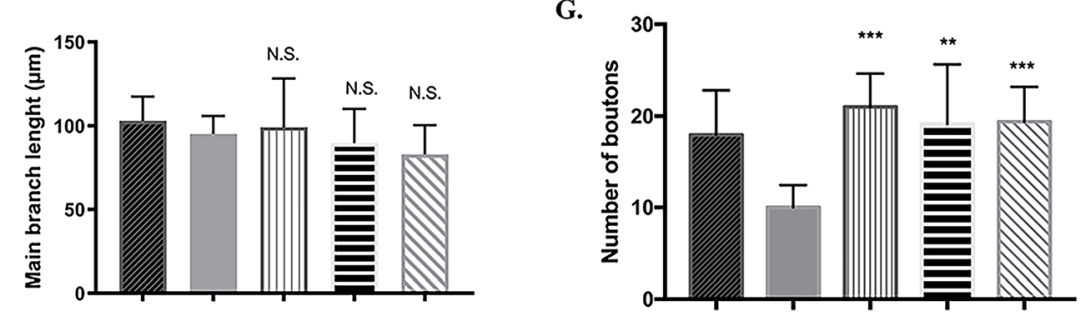

H.
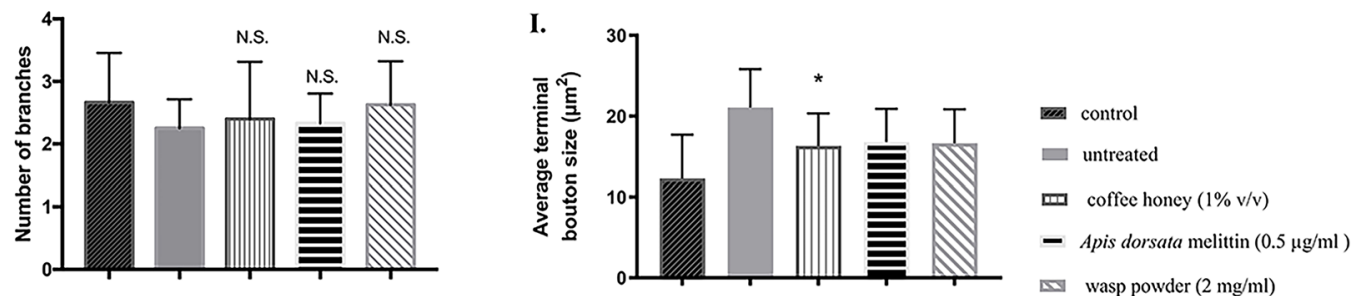

Fig. 3 (See legend on next page.) 
(See figure on previous page.)

Fig. 3 Effects of honeybee products and edible insect powders on synaptic structures. The synaptic structures of control larvae (W; UAS-GFPIR/ +;elav-GAL4/+) (a), pan neuron-specific dUban knockdown larvae ( $w_{;}$UAS-dUbqn/R $107-494 /$; elav-GAL4) without treatment (b), with coffee honey treatment $(\mathbf{c})$, Apis dorsata melittin treatment $(\mathbf{d})$, and wasp powder treatment (e) were shown. HRP and Dlg which are pre- and post-synaptic markers were observed in green and red signals, respectively. The quantification of the main branch length (f), number of boutons $(\mathbf{g})$, number of branches (h), and average terminal boutons size (i) was performed by ImageJ. Quantification results represent the mean \pm SEM. ${ }^{*} p<0.05,{ }^{* *} p<$ $0.01,{ }^{* *} p<0.001$, N.S. not significant. Scale bar is $30 \mu \mathrm{m}$. ( $n=10$ larvae per group)

larval NMJs contain mammalian homologues of glutamate receptors (GluRs) and also postsynaptic structures that resemble to mammalian models [64], we took this advantage to examine our insect products. It was found that among the tested 15 insect extracts and products, three treatments (coffee honey $(1 \% \mathrm{v} / \mathrm{v})$ from $A$. cerana, A. dorsata melittin $(0.5 \mu \mathrm{g} / \mathrm{ml})$, and wasp powder $(2 \mathrm{mg} /$ $\mathrm{ml})$ ) were the most effective at rescuing defects in the locomotive abilities of $d U b q n$ knockdown flies. Furthermore, dUbqn knockdown flies fed with coffee honey (1\% $\mathrm{v} / \mathrm{v}$ ) at least partially rescued synapse structural defects in the NMJs, improved learning ability, and reduced the accumulation of reactive oxygen species (ROS) caused by $d U b q n$ depletion in the brain. In contrast, $A$. dorsata melittin and wasp powder exerted no suppressive effect on the defects in synapse structure and learning ability. Therefore, the improving effects of $A$. dorsata melittin and wasp powder on locomotive defects may be due to effects on some other pathways than the neuronal function such as energy production and muscular development. Further analyses are needed to clarify this point. From the results of our study we found that honey from coffee blossom effectively rescued the defects in behavior of mutant dUbqn larval flies. Coffee honey from $A$. cerana may be the potential candidate for the development of novel therapy for ALS/FTD patients.

Honey is a well-known natural product that is derived from honeybees. Worker honeybees collect nectar from blossoms and store them in a honey sack before they return to the hive. The nectar is then mixed with enzymes from honeybees to breakdown complex sugars in the nectar to simple sugars, such as glucose and fructose [65]. In addition to its sugar content, honey contains various molecules, including proteins and amino acids, trace amounts of enzymes, vitamins, and other substances, such as phenolic compounds [66]. Previous studies on honey clarified its biological properties, such as its antioxidant, anti-inflammatory, anti-bacterial, antiviral, and antiulcer activities as well as its antihyperlipidemic, anti-diabetic, and anti-cancer properties [14, 15, 67, 68]. Recent studies on Tualang honey, which is produced by giant honeybee (Apis dorsata) hives on Tualang trees located mainly in the north-western region of Peninsular Malaysia revealed that honey may exhibit significant activity against chronic cerebral hypoperfusion, which is partially responsible for Alzheimer's disease [69]. Tualang honey has been reported to exert protective effects on learning and memory, accompanied

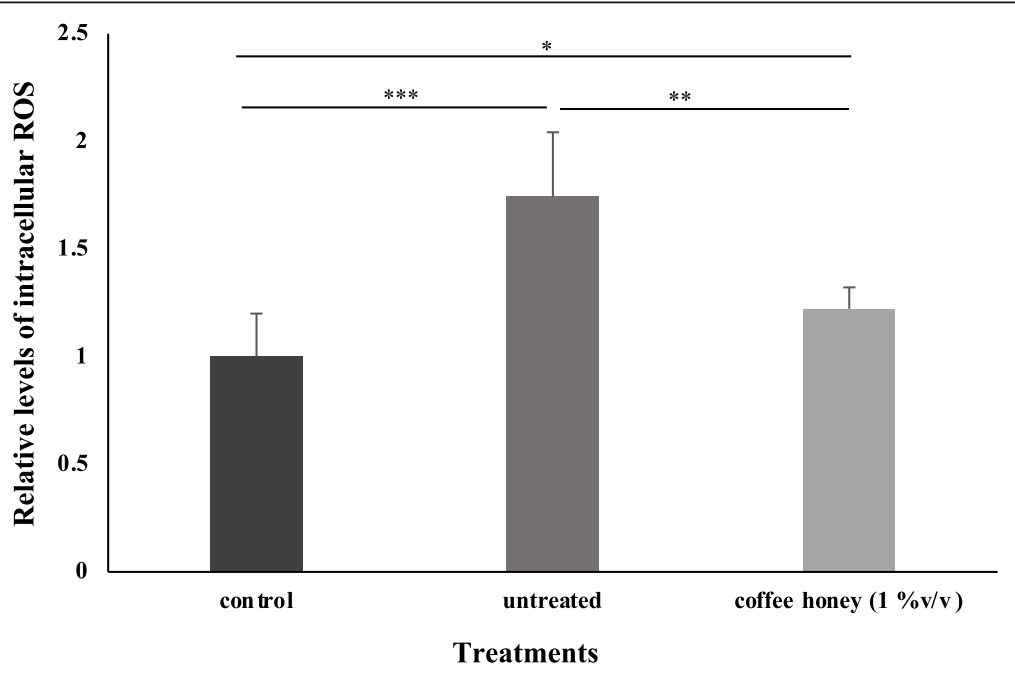

Fig. 4 Reactive oxygen species (ROS) generation in response to coffee honey. The ROS levels of the control larvae ( $w$; UAS-GFPIR/+;elav-GAL4/+), dUban knockdown larvae ( $w_{\text {; UAS-dUbqnIR }}$ U7-494/+elav-GAL4) without treatment and with coffee honey treatment were measured using fluorescence emitted by dichlorofluorescein (DCF). Quantification results represent mean \pm SEM. ${ }^{*} p<0.05,{ }^{* *} p<0.01,{ }^{* * *} p<0.001$. ( $n=3$ of 20 larvae per group) 
by enhancements in the morphology of memory-related brain areas, increased levels of brain-derived neurotrophic factors, reduced brain oxidative stress, increased acetylcholine concentrations, and reduced acetylcholinesterase activity in brain homogenates [28, 70]. Thailand has various types of honey from various flowers, such as longan, coffee, lychee, sunflowers and wildflowers. According to previous report, coffee honey produced by $A$. cerana exhibited strong antioxidant activity $\left(\mathrm{IC}_{50}=\right.$ $1.788 \pm 0.329 \mathrm{mg} / \mathrm{ml}$ ), reflecting stronger free radicalreducing activity [9]. In addition, coffee honey produced by $A$. cerana possessed the highest phenolic $(1308.62 \pm$ $27.83 \mathrm{mg} \mathrm{GAE} / \mathrm{kg})$ and flavonoid contents $(0.152 \pm 0.015$ $\mathrm{mg} \mathrm{QE} / \mathrm{g}$ ) [9]. Furthermore, the volatile compounds (e.g. 2-furanmethanol, butyryl lactone, phenyl methanol, anisaldehyde, anise alcohol, and 3,4,5-trimethyl-phenol) found in coffee honey produced by $A$. cerana may contribute to its antioxidant activity [16].

Since 2011, mutation in a human $U B Q L N 2$ gene has been found to be associated with ALS/FTD (Amyotrophic Lateral Sclerosis/Frontotemporal dementia), the fatal neurodegenerative disease that progressively affected neuronal cells in both brain and spinal cord [49]. The lack of $U B Q L N s$ availability not only caused ALS/ FTD, it also globally affected neuronal functions and makes the neurons more susceptible to various stressors. Previous studies have shown that knockdown of $d U b q n$ flies led to detergent-insoluble ubiquitinated proteins and affected negative geotaxis in $d U b q n$ knockdown flies [54, 71, 72]. Interestingly, Drosophila model of TDP-43 proteinopathy in motor neurons and glia cells showed the improvement of locomotive defects after high glucose consumption [73]. Indeed, TDP-43 proteinopathy was also expressed in $d U b q l n$ knockdown model [71]. Thus, it might be assumed that dUbqn knockdown flies could have some benefits of sugar consumption especially honey which contains high nutrition. However, our study revealed that, not all kinds of honey gave benefits to the dUbqn knockdown model, only coffee honey significantly has this ability. Oxidative stress is one of the mechanisms by which motor neuron death occurs [74]. The polyphenol ingredients of honey may quench the ROS that lead to neurotoxicity, aging, and the pathological deposition of misfolded proteins, including amyloid $\beta$ [26].

Recently, we have found that pan-neuronal $d U b q n$ knockdown flies show significantly altered pre- and post-synaptic structural NMJ proteins by attenuating signals of Bruchpilot puncta and Glutamate receptor IIA clustering [72]. The $d U b q n$-knockdown flies also show a decrease in glutamate, an excitatory neurotransmitter, and increase in GABA, an inhibitory neurotransmitter, which is consistent with the phenotype of the dUbqnknockdown flies [72]. Further analyses on the effect of coffee honey on distribution of these structural NMJ proteins together with the levels and distributions of neurochemicals would be interesting.

\section{Conclusion}

In conclusion, we utilized the $d U b q n$ knockdown model to test the effects of several insects and insect-related products and found that coffee honey effectively rescued the defects in locomotive ability, improved learning ability, and reduced the accumulation of reactive oxygen species (ROS) caused by dUbqn depletion in the brain. Furthermore, the coffee honey could also partially rescue the morphological defects in neuromuscular junction (NMJ) of the dUbqn knockdown flies. Several bioactive compounds or nutritive value in honey might be responsible for these effects. The present results suggest that the synergistic effects of coffee honey will ultimately contribute to the development of effective therapy for neurodegenerative disease. Thus, the coffee honey could be one of the promising insect-derived products which is worth to further investigate and develop in term of medicinal products. This discovery is significant because there is currently no cure or effective treatment options for ALS. Further study in other models is necessary to clarify and investigate deeply the underlying mechanisms.

\section{Supplementary information}

Supplementary information accompanies this paper at https://doi.org/10. 1186/s12906-020-03054-8.

Additional file 1: Table S1 and S2. The concentration of honeybee product and edible insect powder samples, and larval crawling path for dUban knockdown larvae.

Additional file 2: Figure S1. Quantification of dUban mRNA levels in control and untreated dUban knockdown flies. The dUban mRNA expression levels were normalized to RpL32 mRNA levels (* $p<0.05$ ).

\section{Abbreviations}

ALS: Amyotrophic lateral sclerosis; FTD: Frontotemporal dementia; NMJ: Neuromuscular junction; ROS: Reactive oxygen species; FALS: Familial cases of amyotrophic lateral sclerosis; FTLD: Frontotemporal lobar dementia; PBS: Phosphate-buffered saline; F: Forward primer; R: Reverse primer; SUC: Sucrose; OCT: 1-octanol; AM: n-Amyl acetate; LI: Learning index; FITC: Fluorescein isothiocyanate; HRP: Horseradish peroxidase; Dlg: Disc large; $\mathrm{H}_{2}$ DCFDA: 2',7'-dihydrofluorescein diacetate; $I C_{50}$ : Half maximal inhibitory concentration; QE: Quercetin equivalents; GAE: Gallic acid equivalent; VOCs: Volatile organic compounds; ADM: Apis dorsata melittin; ACM: Apis cerana melittin; AFM: Apis florea melittin; CH: Coffee honey; LH: Longan honey; TP: Tea pollen; FDRJ: Freeze-dried fresh royal jelly; Ci: Cicada powder; Si: Silkworm powder; Ba: Bamboo borer powder; Be: Honeybee larva powder; Gi: Giant water bug power; Cr: Crickets powder; Wa: Wasp power;

Su: Subterranean ants powder

\section{Acknowledgements}

The authors acknowledge Professor Dr. Kaeko Kamei (Kyoto Institute of Technology) for providing support and guidance for measurement of reactive oxygen species (ROS) levels. We also thank Medical English Service for the English language review. 


\section{Authors' contributions}

PC and YM conceived the study and acquired funding. PC functioned as a principal investigator of the research project. PC, YM, SJ, and HY designed experiments. PP, JK, and SJ performed experiments. PP, PC, JK and SJ analysed data. PP, PC, MY, SJ, HY wrote and revised the manuscript. All authors edited and approved the final version.

\section{Funding}

PP and PC thank to CMU 50 th Anniversary Ph.D grant and JSPS Core-to-Core Program B, Asia-Africa Science Platforms. PC acknowledge Agricultural Research Development Agency (ARDA) for their financial support of the project and the KIT-CMU collaboration. This research work was partially supported by Chiang Mai University fund to PC. SJ acknowledges Advanced Insect Research Promotion Center (AIRPC) Grant Number 2020008. The funding bodies played no role in the design of the study and collection, analysis, and interpretation of data and in writing a manuscript.

\section{Availability of data and materials}

All data generated during this study are included in this article.

\section{Ethics approval and consent to participate}

Not applicable.

\section{Consent for publication}

Not applicable.

\section{Competing interests}

The authors declared that there are no competing interests.

\section{Author details}

'Graduate School, Chiang Mai University, A. Meung, Chiang Mai 50200, Thailand. ${ }^{2}$ Bee Protection laboratory, Department of Biology, Faculty of Science, Chiang Mai University, A. Meung, Chiang Mai 50200, Thailand. ${ }^{3}$ Department of Applied Biology, Kyoto Institute of Technology, Matsugasaki, Sakyo-ku, Kyoto 606-8585, Japan. ${ }^{4}$ Department of Pharmacology, Faculty of Medicine, Chiang Mai University, A. Meung, Chiang Mai 50200, Thailand. ${ }^{5}$ Department of Biochemistry, Faculty of Medicine, Chiang Mai University, A. Meung, Chiang Mai 50200, Thailand. ${ }^{6}$ The Center for Advanced Insect Research, Kyoto Institute of Technology, Matsugasaki, Sakyo-ku, Kyoto 606-8585, Japan. 'Environmental Science Research Center, Faculty of Science, Chiang Mai University, A. Meung, Chiang Mai 50200, Thailand.

\section{Received: 22 February 2020 Accepted: 12 August 2020}

\section{Published online: 31 August 2020}

\section{References}

1. Williams JP, Williams JR, Kirabo A, Chester D, Peterson M. Chapter 3 nutrient content and health benefits of insects. In: Dossey AT, MoralesRamos JA, Rojas MG, editors. Insects as sustainable food ingredients. San Diego: Academic; 2016. p. 61-84.

2. Rumpold BA, Schlüter OK. Nutritional composition and safety aspects of edible insects. Mol Nutr Food Res. 2013;57(5):802-23.

3. Mijanur Rahman M, Gan SH, Khalil MI. Neurological effects of honey: current and future prospects. Evid Based Complement Alternat Med. 2014;2014: 958721.

4. Fratellone $\mathrm{P}$, Tsimis F, Fratellone G. Apitherapy products for medicinal use. J Altern Complement Med. 2016;22(12):423.

5. Cornara L, Biagi M, Xiao J, Burlando B. Therapeutic properties of bioactive compounds from different honeybee products. Front Pharmacol. 2017;8:412.

6. Russell KM, Molan PC, Wilkins AL, Holland PT. Identification of some antibacterial constituents of New Zealand manuka honey. J Agric Food Chem. 1990;38:10-3.

7. Weston RJ, Brocklebank LK, Lu Y. Identification and quantitative levels of antibacterial components of some New Zealand honeys. Food Chem. 2000; 70(4):427-35.

8. Isla MI, Craig A, Ordoñez R, Zampini C, Sayago J, Bedascarrasbure E, Alvarez A, Salomón V, Maldonado L. Physico chemical and bioactive properties of honeys from northwestern Argentina. LWT-J Food Sci Technol. 2011;44(9): 1922-30.

9. Pattamayutanon P, Angeli S, Thakeow P, Abraham J, Disayathanoowat T, Chantawannakul P. Biomedical activity and related volatile compounds of
Thai honeys from 3 different honeybee species. J Food Sci. 2015;80(10): M2228-40.

10. Hall CA III, Cuppett SL. Structure-activities of natural antioxidants. In: Aruoma $\mathrm{Ol}$, Cuppett SL, editors. Antioxidant Methodology - in vivo and in vitro concepts. Illinois: AOCS Press; 1997. p. 141-72.

11. Bogdanov S, Jurendic T, Sieber R, Gallmann P. Honey for nutrition and health: a review. Am Coll Nutr. 2009;27:677-89.

12. Hossen MS, Ali MY, Jahurul MHA, Abdel-Daim MM, Gan SH, Khalil Ml. Beneficial roles of honey polyphenols against some human degenerative diseases: a review. Pharmacol Rep. 2017;69(6):1194-205.

13. Al-mamary M. A-mA, and Al-habori M: antioxidant activities and total phenolic of different types of honey. Nutr Res. 2002;22:1041-7.

14. Patricia V, Deliza R, Pérez A. How a Huottuja (Piaroa) community perceives genuine and false honey from the Venezuelan Amazon, by free-choice profile sensory method. Rev Bras Farmacogn. 2011;21:786-92.

15. Vit P, Uddin J, Zuccato V, Maza F, Schievano E. Entomological origin of honey discriminated by NMR chloroform extracts in Ecuadorian honey. Int J Biol Biomol Agric Food Biotechnol Eng. 2015;9(5):495-7.

16. Pattamayutanon P, Angeli S, Thakeow P, Abraham J, Disayathanoowat T, Chantawannakul P. Volatile organic compounds of Thai honeys produced from several floral sources by different honey bee species. PLoS One. 2017; 12(Suppl 2):e0172099.

17. Costa-Neto EM. The use of insects in folk medicine in the state of Bahia, northeastern Brazil, with notes on insects reported elsewhere in Brazilian folk medicine. Hum Ecol. 2002;30:245-63.

18. Costa-Neto EM. Entomotherapy, or the medicinal use of insects. J Ethnobiol. 2005;25:93-114.

19. Zimian D, Yonghua Z, Xiwu G. Medicinal insects in China. Ecol Food Nutr. 1997;36(2-4):209-20.

20. Sherman RA, Hall MJR, Thomas S. Medicinal maggots: an ancient remedy for some contemporary afflictions. Rev Entomol. 2000;45:55-81.

21. Alves RRN, Alves HN. The faunal drugstore. Animal-based remedies used in traditional medicines in Latin America. J Ethnobiol Ethnomed. 2011;7:9.

22. Spagnuolo C, Russo M, Bilotto S, Tedesco I, Laratta B, Russo GL. Dietary polyphenols in cancer prevention: the example of the flavonoid quercetin in leukemia. Ann N Y Acad Sci. 2012;1259:95-103.

23. Haffejee IE, Moosa A. Honey in the treatment of infantile gastroenteritis. $\mathrm{Br}$ Med J (Clin Res Ed). 1985;290:1866-7.

24. Ezz El-Arab AM, Girgis SM, Hegazy EM, Abd El-Khalek AB. Effect of dietary honey on intestinal microflora and toxicity of mycotoxins in mice. BMC Complement Altern Med. 2006;6:6.

25. Kamaruzaman NA, Sulaiman SA, Kaur G, Yahaya B. Inhalation of honey reduces airway inflammation and histopathological changes in a rabbit model of ovalbumin-induced chronic asthma. BMC Complement Altern Med. 2014;14:176.

26. Akanmu MA, Olowookere TA, Atunwa SA, Ibrahim BO, Lamidi OF, Adams PA, Ajimuda BO, Adeyemo LE. Neuropharmacological effects of Nigerian honey in mice. Afr J Tradit Complement Altern Med. 2011;8(3):230-49.

27. Simon A, Traynor K, Santos K, Blaser G, Bode U, Molan P. Medical honey for wound care--still the 'latest resort'? Evid Based Complement Alternat Med. 2009;6(2):165-73.

28. Al-Rahbi B, Zakaria R, Othman Z, Hassan A, Mohd Ismail ZI, Muthuraju S. Tualang honey supplement improves memory performance and hippocampal morphology in stressed ovariectomized rats. Acta Histochem. 2014;116:79-88.

29. Yang X-Y, Yang D-S, Wei Z, Wang J-M, Li C-Y, Hui Y, Lei K-F, Chen X-F, Shen $\mathrm{N}-\mathrm{H}$, Jin L-Q, et al. 10-Hydroxy-2-decenoic acid from royal jelly: a potential medicine for RA. J Ethnopharmacol. 2010;128(2):314-21.

30. Conconi JRE. And Jose' MP. The utilization of insects in the empirical medicine of ancient Mexicans. J Ethnobiol. 1988;8:195-202.

31. Šver L, Oršolić N, Tadić Z, Njari B, Valpotic I, Bašic I. A royal jelly as a new potential immunomodulator in rats and mice. Comp Immunol Microbiol Infect Dis. 1996;19:31-8.

32. Okamoto I, Taniguchi Y, Kunikata T, Kohno K, Iwaki K, Ikeda M, Kurimoto M. Major royal jelly protein 3 modulates immune responses in vitro and in vivo. Life Sci. 2003;73(16):2029-45.

33. Calli C, Tugyan K, Oncel S, Pinar E, Demirtaşoglu F, Calli A, Tolon B, Yilmaz O, Kiray A. Effectiveness of Royal Jelly on tympanic membrane perforations: an experimental study. J Tolaryngol Head Neck Surg. 2008;37(2):179-84.

34. Lee SH, Choi SM, Yang EJ. Melittin ameliorates the inflammation of organs in an amyotrophic lateral sclerosis animal model. Exp Neurol. 2014;23(1):86-92. 
35. Chen J, Guan S-M, Sun W, Fu H. Melittin, the major pain-producing substance of bee venom. Neurosci Bull. 2016;32(3):265-72.

36. Choi MS, Park S, Choi T, Lee G, Haam K-K, Hong M-C, Min B-I, Bae H. Bee venom ameliorates ovalbumin induced allergic asthma via modulating CD4+CD25+ regulatory T cells in mice. Cytokine. 2013;61:256-65.

37. Lee $H$, Lee E, Kim H, Lee G, Um EJ, Kim Y, Lee BY, Bae H. Bee venomassociated Th1/Th2 immunoglobulin class switching results in immune tolerance of NZB/W F1 murine lupus nephritis. Am J Nephrol. 2011; 34(2):163-72.

38. Yang EJ, Jiang JH, Lee SM, Yang SC, Hwang HS, Lee MS, Choi S-M. Bee venom attenuates neuroinflammatory events and extends survival in amyotrophic lateral sclerosis models. J Neuroinflammation. 2010;7:69.

39. Cho S-Y, Shim S-R, Rhee HY, Park H-J, Jung W-S, Moon S-K, Park J-M, Ko C-N, Cho K-H, Park S-U. Effectiveness of acupuncture and bee venom acupuncture in idiopathic Parkinson's disease. Parkinsonism Relat Disord. 2012;18(8):948-52.

40. Pranskuniene Z, Bernatoniene J, Simaitiene Z, Pranskunas A, Mekas T. Ethnomedicinal uses of honeybee products in Lithuania. T Evid Based Complement Alternat Med. 2016;2016:9272635.

41. Buck AC, Cox R, Rees RWM, Ebeling L, John A. Treatment of outflow tract obstruction due to benign prostatic hyperplasia with the pollen extract Cernilton. Br J Urol. 1990;66(4):398-404.

42. Almaraz-Abarca N, Campos MG, Ávila-Reyes JA, Naranjo-Jiménez N, HerreraCorral J, Gonzalez-Valdez LS. Variability of antioxidant activity among honeybee-collected pollen of different botanical origin. Interciencia. 2004; 29(10):574-8.

43. Kroyer $\mathrm{G}$, Hegedus $\mathrm{N}$. Evaluation of bioactive properties of pollen extracts as functional dietary food supplement. Innov Food Sci Emerg Technol. 2001; 2(3):171-4.

44. Komosinska-Vassev K, Olczyk P, Kaźmierczak J, Mencner L, Olczyk K. Bee pollen: chemical composition and therapeutic application. Evid Based Complement Alternat Med. 2015;2015:297425.

45. Calvo A, Moglia C, Lunetta C, Marinou K, Ticozzi N, Ferrante GD, Scialo C, Sorarù G, Trojsi F, Conte A, et al. Factors predicting survival in ALS: a multicenter Italian study. J Neurol. 2017;264:54-63.

46. Kim SH, Stiles SG, Feichtmeier JM, Ramesh N, Zhan L, Scalf MA, Smith LM, Pandey UB, Tibbetts RS. Mutation-dependent aggregation and toxicity in a Drosophila model for UBQLN2-associated ALS. Hum Mol Genet. 2017;27:322-37.

47. Markovinovic A, Cimbro R, Ljutic T, Kriz J, Rogelj B, Munitic I. Optineurin in amyotrophic lateral sclerosis: multifunctional adaptor protein at the crossroads of different neuroprotective mechanisms. Prog Neurobiol. 2017; 154:1-20.

48. Tresse E, Salomons F, Vesa J, Bott L, Kimonis V, Yao T-P, Dantuma N, Taylor JP. VCP/p97 is essential for maturation of ubiquitin-containing autophagosomes and this function is impaired by mutations that cause IBMPFD. Autophagy. 2010;6:217-27.

49. Deng H-X, Chen W, Hong S-T, Boycott KM, Gorrie GH, Siddique N, Yang Y, Fecto $F$, Shi $Y$, Zhai $H$, et al. Mutations in UBQLN2 cause dominant X-linked juvenile and adult-onset ALS and ALS/dementia. Nature. 2011;477:211-5.

50. Massey L, Mah A, Ford D, Miller J, Liang J, Doong H, Monteiro M. Overexpression of ubiquilin decreases ubiquitination and degradation of presenilin proteins. J Alzheimers Dis. 2004;6:79-92.

51. Lloyd TE, Taylor JP. Flightless flies: Drosophila models of neuromuscular disease. Ann N Y Acad Sci. 2010;1184:E1-20

52. Reiter LT, Potocki L, Chien S, Gribskov M, Bier E. A systematic analysis of human disease-associated gene sequences in Drosophila melanogaster. Genome Res. 2001;11(6):1114-25.

53. Li A, Xie Z, Dong Y, McKay KM, McKee ML, Tanzi RE. Isolation and characterization of the Drosophila ubiquilin ortholog dUbq/n : in vivo interaction with early-onset Alzheimer disease genes. Hum Mol Genet. 2007; 16(21):2626-39.

54. Jantrapirom S, Lo Piccolo L, Yoshida H, Yamaguchi M. A new Drosophila model of Ubiquilin knockdown shows the effect of impaired proteostasis on locomotive and learning abilities. Exp Cell Res. 2018;362:461-71.

55. Xia R, Liu Y, Yang L, Gal J, Zhu H, Jia J. Motor neuron apoptosis and neuromuscular junction perturbation are prominent features in a Drosophila model of Fus-mediated ALS. Mol Neurodegener. 2012;7:10.

56. Wobst HJ, Mack KL, Brown DG, Brandon NJ, Shorter J. The clinical trial landscape in amyotrophic lateral sclerosis-past, present, and future. Med Res Rev. 2020;40:1352-33.
57. Yang EJ, Kim SH, Yang SC, Lee SM, Choi S-M. Melittin restores proteasome function in an animal model of ALS. J Neuroinflammation. 2011;8(1):69.

58. Ahmed T, Nawaz M, Iqbal W. Chapter 7 - Pharmacological Effects of Curcuminoids in Neurological Disorders. In: Farooqui T, Farooqui AA, editors. Curcumin for Neurological and Psychiatric Disorders. New York: Academic Press; 2019. p. 129-154.

59. Chantawannakul P. From entomophagy to entomotherapy. Front Biosci (Schol Ed). 2020;25:179-200.

60. Brooks DS, Vishal K, Kawakami J, Bouyain S, Geisbrecht ER. Optimization of wrMTrck to monitor Drosophila larval locomotor activity. J Insect Physiol. 2016;93-94:11-7.

61. Stewart BA, Atwood HL, Renger JJ, Wang J, Wu CF. Improved stability of Drosophila larval neuromuscular preparations in haemolymph-like physiological solutions. J Comp. 1994;175:179-91.

62. Lo Piccolo L, Yamaguchi M. RNAi of arcRNA hsrw affects sub-cellular localization of Drosophila FUS to drive neurodiseases. Exp Neurol. 2017; 292:125-34.

63. Wang H, Luo K, Tan L-Z, Ren B-G, Gu L-Q, Michalopoulos G, Luo J-H, Yu YP. p53-induced gene 3 mediates cell death induced by glutathione peroxidase 3. J Biol. 2012;287(20):16890-902.

64. Menon KP, Carrillo RA, Zinn K. Development and plasticity of the Drosophila larval neuromuscular junction. Wires Dev Biol. 2013;2(5):647-70.

65. Elsheikh ATA. Physicochemical properties of bee honey from different floral origins as compared to those of sugarcane honey: M.Sc Thesis. UOFK: University of Khartoum; 2015. .

66. Al-Qassemi R, Robinson RK. Some special nutritional properties of honey - a brief review. Food Sci Nutr. 2003;33(6):254-60.

67. Erejuwa OO, Sulaiman SA, Wahab MS, Sirajudeen KNS, Salleh MSM, Gurtu S. Antioxidant protection of Malaysian tualang honey in pancreas of normal and streptozotocin-induced diabetic rats. Ann Endocrinol (Paris). 2010;71(4):291-6.

68. Viuda-Martos M, Ruiz-Navajas Y, Fernández-López J, Pérez-Álvarez JA. Functional properties of honey, Propolis, and Royal Jelly. J Food Sci. 2008;73: R117-24.

69. Saxena AK, Phyu H, Al-Ani I, Talib NA. Potential protective effect of honey against chronic cerebral hypoperfusion-induced neurodegeneration in rats. J Anat Soc India. 2014;63:151-5.

70. Othman Z, Shafin N, Zakaria R, Nik Hussain NH, Wan Mohammad WMZ. Erratum: improvement in immediate memory after 16 weeks of tualang honey (agro mas) supplement in healthy postmenopausal women. Menopause. 2011;18:1219-24.

71. Jantrapirom S, Lo Piccolo L, Yoshida H, Yamaguchi M. Depletion of Ubiquilin induces an augmentation in soluble ubiquitinated Drosophila TDP-43 to drive neurotoxicity in the fly. Biochim Biophys Acta. 2018; 1864(9):3038-49.

72. Jantrapirom S, Enomoto Y, Karinchai J, Yamaguchi M, Yoshida H, Fukusaki E, Shimma S, Yamaguchi M. The depletion of ubiquilin in Drosophila melanogaster disturbs neurochemical regulation to drive activity and behavioral deficits. Sci Rep. 2020;10:5689.

73. Manzo E, Lorenzini I, Barrameda D, O'Conner A, Barrows J, Starr A, Kovalik T, Rabichow B, Lehmkuhl E, Shreiner D, et al. Glycolysis upregulation is neuroprotective as a compensatory mechanism in ALS. eLife. 2019;8:e45114.

74. Barber SC, Mead RJ, Shaw PJ. Oxidative stress in ALS: a mechanism of neurodegeneration and a therapeutic target. Biochim Biophys Acta. 2006; 1762(11-12):1051-67.

\section{Publisher's Note}

Springer Nature remains neutral with regard to jurisdictional claims in published maps and institutional affiliations. 